\title{
Probing Ferromagnetic Shape Memory Alloys in Pt-Based Heusler Compounds
}

\author{
Xiong Yang*, Ying Wang, Mingrun Du and Wendi Zhang \\ College of Science, Civil Aviation University of China, Tianjin 300300, China \\ Received: 03.03.2020 \& Accepted: 23.09.2020
}

Doi: $10.12693 /$ APhysPolA.139.8

*e-mail: $\quad x$-yang@cauc.edu.cn

\begin{abstract}
Using first-principles calculations based on density functional theory, we have investigated the structural, magnetic, electronic and mechanical properties of the Heusler alloys, $\mathrm{Pt}_{2} \mathrm{YAs}$ and $\mathrm{Pt}_{2} \mathrm{YSb}_{\mathrm{Sb}}$ ( $\mathrm{Y}$ is not yttrium, $\mathrm{Y}=\mathrm{Cr}, \mathrm{Mn}, \mathrm{Fe}$ and $\mathrm{Co}$ ). In the austenite phases, these alloys have a regular structure with a negative formation energy. The magnetic coupling between the transition metal atoms is ferromagnetic. All the compounds are found to be prone to transforming from austenite to martensite, on the basis of analyzing the energy, density of states and tetragonal shear modulus. Among the alloys, $\mathrm{Pt}_{2} \mathrm{YAs}$ and $\mathrm{Pt}_{2} \mathrm{YSb}(\mathrm{Y}=\mathrm{Mn}, \mathrm{Fe}$ and $\mathrm{Co})$ are predicted to have high martensitic transition temperatures which are not only above room temperature but much higher than that of the well-known $\mathrm{Ni}_{2} \mathrm{MnGa}$ material. All the Pt-based alloys are more ductile than $\mathrm{Ni}_{2} \mathrm{MnGa}$.
\end{abstract}

topics: first-principles calculation, ferromagnetic shape memory alloy, martensitic phase transition, mechanical property

\section{Introduction}

Full-Heusler alloys are ternary intermetallic compounds with a general $\mathrm{X}_{2} \mathrm{YZ}$ formula, commonly crystallizing in an $L 2_{1}$ structure. $\mathrm{X}$ is a transition metal atom, $\mathrm{Y}$ is a magnetically active transition metal atom and $\mathrm{Z}$ is the main group element. Ferromagnetic shape memory alloys (FSMAs) are a class of full-Heusler compounds showing both ferromagnetism and a shape memory effect. As the most famous member of FSMAs, $\mathrm{Ni}_{2} \mathrm{MnGa}$ exhibits a great potential for technological applications because of its diverse functional properties: a large magnetic field-induced strain (MFIS) effect [1-3], a huge magneto-caloric effect (MCE) $[4,5]$ and a large magneto-resistance effect [6]. However, there exist two problems in the case of a practical application of $\mathrm{Ni}_{2} \mathrm{MnGa}$ : its low martensitic transition temperature $T_{M}$ and high brittleness. Therefore, the present challenge is to probe new FSMAs with higher $T_{M}$ and better ductility.

The effects of substitution at $\mathrm{Ni}, \mathrm{Mn}$ and Ga sites in $\mathrm{Ni}_{2} \mathrm{MnGa}$ with various other elements have been intensively studied. For example, partial $\mathrm{Cu}$ doping at the $\mathrm{Mn}$ and Ga sites can increase the $T_{M}[7]$. Furthermore, the replacement of $\mathrm{Mn}$ by $\mathrm{Cu}$ can create a giant magnetocaloric effect $[8,9]$. An MFIS of $12 \%$ was observed in the nonmodulated martensite of $\mathrm{Ni}_{2} \mathrm{MnGa}$ simultaneously doped with $\mathrm{Cu}$ and Co [10]. Especially, Pt doping effects in $\mathrm{Ni}_{2} \mathrm{MnGa}$ have attracted much attention in recent years. First-principles calculations predicted a maximal
MFIS of $14 \%$ in the $\mathrm{Ni}_{1.75} \mathrm{Pt}_{0.25} \mathrm{MnGa}$ system [11]. Furthermore, a sizeable magnetocaloric effect and the magnetocrystalline anisotropy (MAE) were observed in $\mathrm{Ni}_{2-x} \mathrm{Pt}_{x} \mathrm{MnGa}[12,13]$. Investigations on $\mathrm{Ni}_{2-x} \mathrm{Pt}_{x} \mathrm{MnGa}$ show that in fact the $T_{M}$ increases, while the $\mathrm{Pt}$ content increases up to $\mathrm{Ni}_{1.6} \mathrm{Pt}_{0.4} \mathrm{MnGa}[11,14,15]$. For the situation of complete $\mathrm{Pt}$ substitution in the $\mathrm{Ni}$ site, the $\mathrm{Pt}_{2} \mathrm{MnGa}$ alloy was found to have not only a higher $T_{M}$ and better ductility but also stronger ferromagnetism when compared to $\mathrm{Ni}_{2} \mathrm{MnGa}$ [16-18]. In fact, $\mathrm{Pt}_{2} \mathrm{CrGa}$ and $\mathrm{Pt}_{2} \mathrm{FeGa}$ have demonstrated their potential for FSMAs [16-18].

In this work, we studied the structural, magnetic, electronic and mechanical properties of full-Heusler alloys, $\mathrm{Pt}_{2} \mathrm{YAs}$ and $\mathrm{Pt}_{2} \mathrm{YSb}$, using first-principles calculations. For the $\mathrm{Y}$ atom, we consider four typical $2 d$ transition metal atoms with high atomic moments, namely, Cr, Mn, Fe and Co. The main purpose of this paper is to investigate the possibility of the austenite-martensite transitions for the $\mathrm{Pt}_{2} \mathrm{YAs}$ and $\mathrm{Pt}_{2} \mathrm{YSb}$ alloys. We intend to explore the electronic and mechanical mechanism of the martensitic phase transition. Furthermore, the martensitic transition temperatures are calculated and the ductility is estimated.

\section{Method}

In this paper, we carried out the first-principles calculations using the CASTEP code $[19,20]$ based on the density functional theory [21-29]. For the 
Heusler alloys studied here, the exchange correlation functional was calculated with the PerdewBurke-Enzerhof of generalized gradient approximation [30]. We used the energy cut-off of $500 \mathrm{eV}$ for the plane waves and the $k$ mesh of $15 \times 15 \times 15$ for sampling the irreducible Brillouin zone of the austenite phase.

The elastic constants of a material can describe its response to an imposed stress. Both the stress and strain possess three tensile and three shear components which provide six components in total. Small stresses $\sigma$ and strains $\varepsilon$ are interrelated based on the formula $\sigma_{i}=C_{i j} \varepsilon_{j}$, according to the generalized Hooke law. The elastic constants $C_{i j}$ can be calculated from the second derivative of the energy with respect to the strain tensor.

\section{Results and discussion}

\subsection{Cubic structure and relative crystal stability}

For the austenite phase of the full-Heusler alloys studied here, we take into account two $L 2_{1}$ structure types, namely, the regular structure crystallizing in the space group $F m \overline{3} m$ (No. 225) and the inverse structure with the space group $F \overline{4} 3 m$ (No. 216). In a 16-atom unit cell of the regular structure, the Wyckoff positions $1 / 4,1 / 4,1 / 4$ ) and $(3 / 4,3 / 4,3 / 4)$ are equivalent, which are occupied with two $\mathrm{Pt}$ atoms, while the other sites $(1 / 2,1 / 2,1 / 2)$ and $(0,0,0)$ are filled with $\mathrm{Y}$ and As (Sb) atoms, respectively. For the inverse structure,

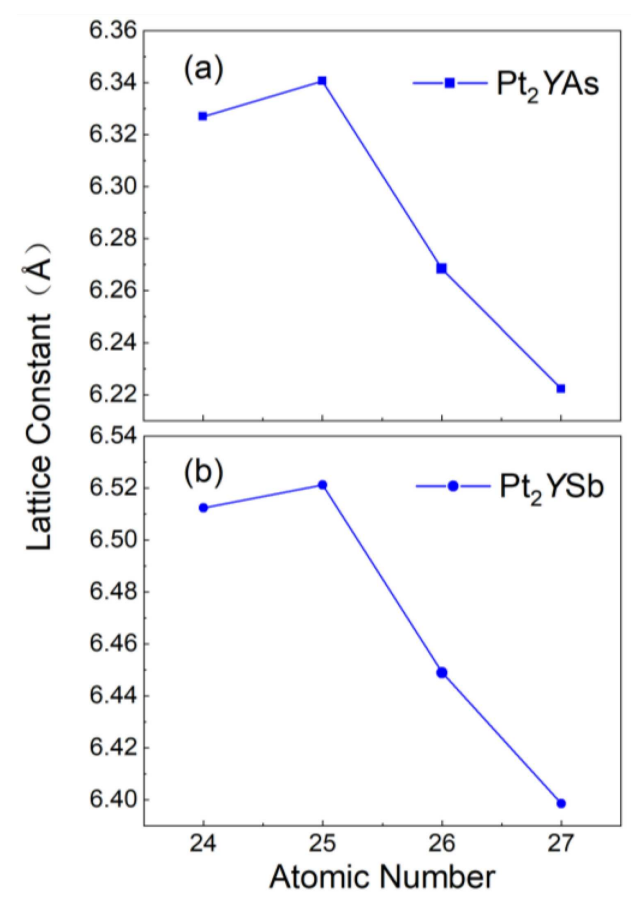

Fig. 1. Lattice constants of the cubic phases as a function of the atomic number of $\mathrm{Y}$ element for the $\mathrm{Pt}_{2} \mathrm{YAs}$ and $\mathrm{Pt}_{2} \mathrm{YSb}(\mathrm{Y}=\mathrm{Cr}, \mathrm{Mn}, \mathrm{Fe}$ and $\mathrm{Co})$ alloys.

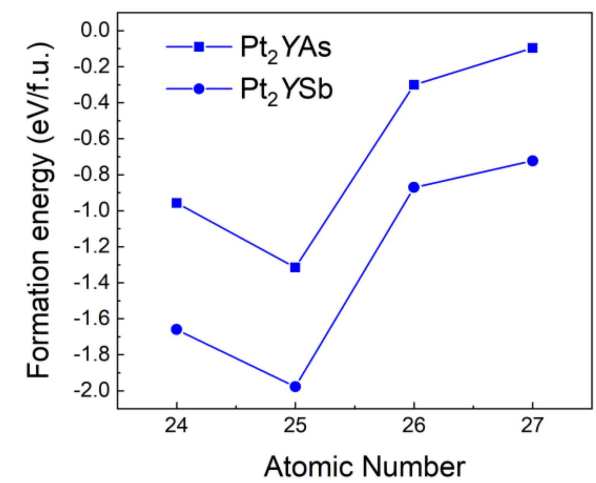

Fig. 2. Formation energies of the cubic phases as a function of the atomic number of $\mathrm{Y}$ element for the $\mathrm{Pt}_{2} \mathrm{YAs}$ and $\mathrm{Pt}_{2} \mathrm{YSb}(\mathrm{Y}=\mathrm{Cr}, \mathrm{Mn}, \mathrm{Fe}$ and $\mathrm{Co})$ alloys.

four Wyckoff sites are inequivalent, which are occupied with $\mathrm{Pt}$ at $(1 / 4,1 / 4,1 / 4)$, Y at $(3 / 4,3 / 4,3 / 4)$, $\mathrm{Pt}$ at $(1 / 2,1 / 2,1 / 2)$ and $\mathrm{As}(\mathrm{Sb})$ at $(0,0,0)$. Based on the geometry optimization, we find that for all the $\mathrm{Pt}_{2} \mathrm{YAs}$ and $\mathrm{Pt}_{2} \mathrm{YSb}$ alloys, the regular structures have smaller total energies than the inverse structures. Thus, the cubic structures of the alloys are the regular structure. This result is in agreement with the previous observation of $\mathrm{Pt}_{2} \mathrm{CrGa}$, $\mathrm{Pt}_{2} \mathrm{MnGa}, \mathrm{Pt}_{2} \mathrm{FeGa}[16,17]$ and $\mathrm{Pt}_{2} \mathrm{MnIn}$ [31]. Figure 1 indicates the lattice constants of the cubic structures of the $\mathrm{Pt}_{2} \mathrm{YAs}$ and $\mathrm{Pt}_{2} \mathrm{YSb}$ compounds. It is noted that two series $\mathrm{Pt}_{2} \mathrm{YAs}$ and $\mathrm{Pt}_{2} \mathrm{YSb}$ share a similar variation trend of the lattice constants with the $\mathrm{Y}$ atom varying from $\mathrm{Cr}$ to Co. The lattice constant of $\mathrm{Ni}_{2} \mathrm{MnGa}$ is also calculated and our obtained data of $5.838 \AA$ agrees well with the experimental value of $5.832 \AA[32]$.

The formation energy of the material can be used to analyze the relative crystal stability [16-18]. We calculate the formation energies of the $\mathrm{Pt}_{2} \mathrm{YAs}$ and $\mathrm{Pt}_{2} \mathrm{YSb}$ Heusler alloys, using

$$
E_{\text {tot }}^{(\mathrm{Pt} \mathrm{YZ})}-2 E_{\text {tot }}^{(\mathrm{Pt})}-E_{\text {tot }}^{(\mathrm{Y})}-E_{\text {tot }}^{(\mathrm{Z})} \text {. }
$$

These energies are shown in Fig. 2. It is noted that the formation energies are negative for all the alloys which indicates that all the $\mathrm{Pt}_{2} \mathrm{YAs}$ and $\mathrm{Pt}_{2} \mathrm{YSb}$ alloys are stable electronically. Thus, all the compounds studied here can be synthesized in experiment.

\subsection{Magnetic configuration}

For the magnetic ground states of the austenite phases of the $\mathrm{Pt}_{2} \mathrm{YAs}$ and $\mathrm{Pt}_{2} \mathrm{YSb}$ alloys, we consider three different types of magnetic configurations: ferromagnetic (FM) coupling, ferrimagnetic (FIM) coupling, and non-magnetic (NM) state (resulting from non-spin-polarised computations) between the transition metal atoms $\mathrm{Pt}$ and $\mathrm{Y}$. It is found that for all these alloys, the converged total energy of the FM coupling is smaller than those of the FIM coupling and NM state. Therefore, the magnetic configurations of the cubic ground states 
Total magnetic moments per formula unit of the austenite phase for the $\mathrm{Pt}_{2} \mathrm{YAs}$ and $\mathrm{Pt}_{2} \mathrm{YSb}$ alloys as well as the $\mathrm{Ni}_{2} \mathrm{MnGa}$ alloy. The magnetic moments of the $\mathrm{Y}$ and $\mathrm{Pt}$ atoms in $\mu_{\mathrm{B}}$ are given in the first and second values in parentheses, respectively.

\begin{tabular}{l|l}
\hline \hline Materials & Magnetic moments \\
\hline $\mathrm{Pt}_{2} \mathrm{CrAs}$ & $3.72(3.35,0.15)$ \\
$\mathrm{Pt}_{2} \mathrm{MnAs}$ & $4.42(3.87,0.25)$ \\
$\mathrm{Pt}_{2} \mathrm{FeAs}$ & $3.52(3.10,0.20)$ \\
$\mathrm{Pt}_{2} \mathrm{CoAs}$ & $2.02(1.78,0.12)$ \\
$\mathrm{Pt}_{2} \mathrm{CrSb}$ & $3.87(3.53,0.13)$ \\
$\mathrm{Pt}_{2} \mathrm{MnSb}$ & $4.43(3.96,0.20)$ \\
$\mathrm{Pt}_{2} \mathrm{FeSb}$ & $3.51(3.14,0.16)$ \\
$\mathrm{Pt}_{2} \mathrm{CoSb}$ & $1.77(1.70,0.04)$ \\
$\mathrm{Ni}_{2} \mathrm{MnGa}$ & $4.17(3.28,0.43)$ \\
& $4.096(3.413,0.361)^{a}$ \\
& $4.093(3.296,0.357)^{b}$ \\
\hline
\end{tabular}

${ }^{a}$ Ref. [7], ${ }^{b}$ Ref. [17]

are FM for all the systems. The total and atomic magnetic moments for the alloys in the austenite phases are listed in Table I. It can be seen that the total magnetic moment is mainly contributed by the $\mathrm{Y}$ atom and little by the $\mathrm{Pt}$ atom. Thus, the $\mathrm{Pt}_{2} \mathrm{YAs}$ and $\mathrm{Pt}_{2} \mathrm{YSb}$ alloys with the same $\mathrm{Y}$ atom possess a similar total moment. In two series $\mathrm{Pt}_{2} \mathrm{YAs}$ and $\mathrm{Pt}_{2} \mathrm{YSb}, \mathrm{Pt}_{2} \mathrm{MnAs}$ and $\mathrm{Pt}_{2} \mathrm{MnSb}$ have the largest total moments of about $4.4 \mu_{\mathrm{B}} /$ f.u. which are larger than that of the typical FSMA-like $\mathrm{Ni}_{2} \mathrm{MnGa}$.

\subsection{Martensitic transformation}

Figure 3 shows the curves of the total energy difference $\Delta E$ between the austenite and martensite phases of the $\mathrm{Pt}_{2} \mathrm{YAs}$ and $\mathrm{Pt}_{2} \mathrm{YSb}$ alloys as a function of the $c / a$ ratio. It is found that all the energy curves have a minimum corresponding to the stable martensitic phase. Therefore, all these alloys are prone to undergoing a martensitic phase transition. The tetragonal $c / a$ ratios and the absolute values of $\Delta E$ for the alloys are summarized in Table II. Among the alloys, the phase transition of $\mathrm{Pt}_{2} \mathrm{CoSb}$ occurs at $c / a=1.46$ and for other alloys, the transitions are found at $c / a<1(0.80-0.83)$. In two series $\mathrm{Pt}_{2} \mathrm{YAs}$ and $\mathrm{Pt}_{2} \mathrm{YSb}$, the value of the $c / a$ ratio decreases with the $\mathrm{Y}$ atom changing from $\mathrm{Cr}$ to $\mathrm{Fe}$. The $\Delta E$ in both series of $\mathrm{Pt}_{2} \mathrm{YAs}$ and $\mathrm{Pt}_{2} \mathrm{YSb}$ increases remarkably with the atomic number of the $\mathrm{Y}$ atom increasing, except for $\mathrm{Pt}_{2} \mathrm{CoSb}$. It is to be noted that most of the Pt-based alloys possess a much larger $\Delta E$ than the $\mathrm{Ni}_{2}$-based alloys [17]. The larger the energy difference $\Delta E$, the greater the driving force of the austenite--martensite transition. Thus, we conclude that excess $\mathrm{Pt}$ in the Heusler alloys may be beneficial for stabilizing the martensite phase.
Tetragonal $c / a$ ratio, total energy difference $\Delta E$ between the austenite and martensite, and the martensitic temperature $T_{M}$ for the $\mathrm{Pt}_{2} \mathrm{YAs}$ and $\mathrm{Pt}_{2} \mathrm{YSb}$ alloys.

\begin{tabular}{l|c|c|c}
\hline \hline Materials & $c / a$ & $\begin{array}{c}\Delta E \\
{[\mathrm{meV} / \text { atom }]}\end{array}$ & $T_{M}[\mathrm{~K}]$ \\
\hline $\mathrm{Pt}_{2} \mathrm{CrAs}$ & 0.83 & 14.1 & 163.6 \\
$\mathrm{Pt}_{2} \mathrm{MnAs}$ & 0.82 & 33.5 & 388.6 \\
$\mathrm{Pt}_{2} \mathrm{FeAs}$ & 0.81 & 49.2 & 570.7 \\
$\mathrm{Pt}_{2} \mathrm{CoAs}$ & 0.83 & 54.5 & 632.2 \\
$\mathrm{Pt}_{2} \mathrm{CrSb}$ & 0.82 & 15.4 & 178.6 \\
$\mathrm{Pt}_{2} \mathrm{MnSb}$ & 0.81 & 38.6 & 447.8 \\
$\mathrm{Pt}_{2} \mathrm{FeSb}$ & 0.80 & 64.3 & 745.9 \\
$\mathrm{Pt}_{2} \mathrm{CoSb}$ & 1.46 & 62.5 & 725.0
\end{tabular}

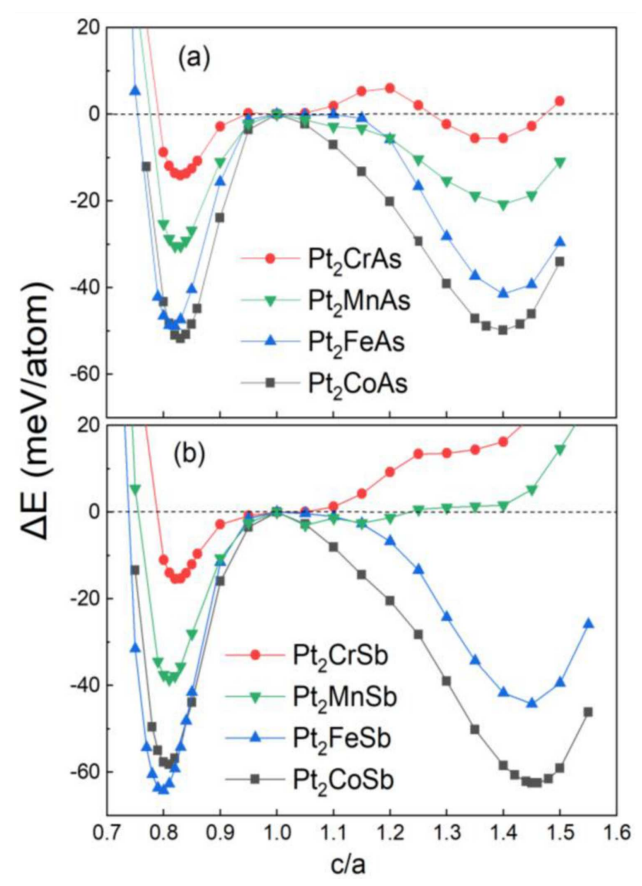

Fig. 3. Total energy difference $\Delta E$ between the austenite and martensite as a function of the $c / a$ ratio for the alloys $\mathrm{Pt}_{2} \mathrm{YAs}(\mathrm{a})$ and $\mathrm{Pt}_{2} \mathrm{YSb}(\mathrm{b})$.

In Table II, we report the transition temperatures $T_{M}$ of the $\mathrm{Pt}_{2} \mathrm{YAs}$ and $\mathrm{Pt}_{2} \mathrm{YSb}$ alloys which are calculated based on the relationship: $\Delta E=k_{\mathrm{B}} T_{M}$ ( $k_{\mathrm{B}}$ is the Boltzmann constant) [33]. As discussed in $[7,18]$, these estimated values of $T_{M}$ may have a certain disparity with the experimental values of the temperatures due to the limitation of the firstprinciples calculations. Our theoretical results exhibit the dependence of the $T_{M}$ on the composition element which may be helpful in the design of new Pt-based FSMAs. We find that among the alloys, $\mathrm{Pt}_{2} \mathrm{YAs}$ and $\mathrm{Pt}_{2} \mathrm{YSb}(\mathrm{Y}=\mathrm{Mn}, \mathrm{Fe}$ and $\mathrm{Co}$ ) have high $T_{M}$ temperatures which are much higher than room temperature and the $T_{M}=202 \mathrm{~K}$ of the well-known FSMA, $\mathrm{Ni}_{2} \mathrm{MnGa}[18]$. 


\subsection{Electronic structure}

In Figs. 4 and 5, we present the total and partial density of states (DOS) for the cubic and tetragonal phases of the $\mathrm{Pt}_{2} \mathrm{YAs}$ and $\mathrm{Pt}_{2} \mathrm{YSb}$ alloys. It can be found that a sharp peak occurs below the Fermi level $E_{\mathrm{F}}$ (at about $-1.0 \mathrm{eV}$ to $-0.5 \mathrm{eV}$ ) in the minority DOS of the cubic phases of the $\mathrm{Pt}_{2} \mathrm{YAs}$ and $\mathrm{Pt}_{2} \mathrm{YSb}(\mathrm{Y}=\mathrm{Cr}, \mathrm{Mn}$ and $\mathrm{Fe}$ ) alloys which comes from hybridization between the $d$ states of the transition metal atoms $\mathrm{Pt}$ and $\mathrm{Y}$. This high value of DOS near $E_{\mathrm{F}}$ in the cubic phase is one of the main causes of the martensitic transition [34, 35]. As shown in Figs. $4 \mathrm{e}-\mathrm{g}$ and $5 \mathrm{e}-\mathrm{g}$, the tetragonal distortion smooths out high peaks near $E_{\mathrm{F}}$. This redistribution of DOS leads to the fact that the total energy of the tetragonal phase is smaller when compared to the cubic phase. For the $\mathrm{Pt}_{2} \mathrm{FeAs}$ alloy (Fig. 4c and g), another electronic factor inducing the instability of the cubic phase are the peaks of $\mathrm{Pt}$ and Fe $d$-states in the majority DOS. In the case of the $\mathrm{Pt}_{2} \mathrm{CoAs}$ and $\mathrm{Pt}_{2} \mathrm{CoSb}$ alloys, the Co $d$ peak near $E_{\mathrm{F}}$ in the cubic phase splits to two peaks after the tetragonal distortion which lowers the total energy.

\subsection{Bulk mechanical properties}

Table III indicates the elastic constants $C_{11}, C_{12}$ and $C_{44}$ as well as the relevant moduli for the cubic phases of the $\mathrm{Pt}_{2} \mathrm{YAs}$ and $\mathrm{Pt}_{2} \mathrm{YSb}$ Heusler alloys. We also present the results of $\mathrm{Ni}_{2} \mathrm{MnGa}$ which

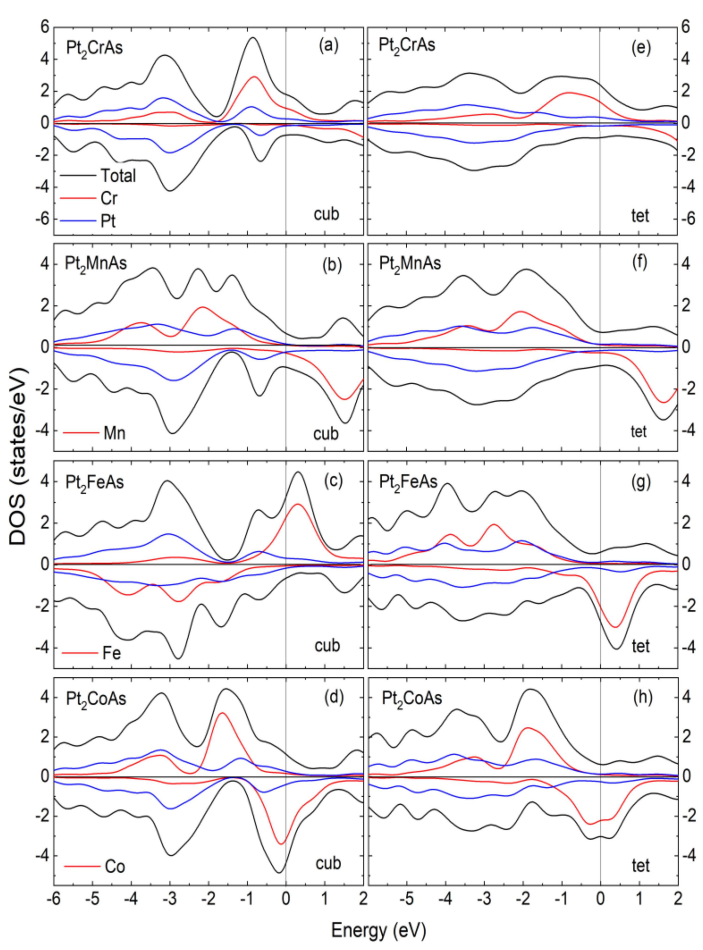

Fig. 4. Total and partial density of states of the cubic (left column) and tetragonal (right column) $\mathrm{Pt}_{2}$ YAs alloys with $\mathrm{Y}=\mathrm{Cr}(\mathrm{a})$ and $(\mathrm{e}), \mathrm{Mn}(\mathrm{b})$ and (f), Fe (c) and (g) and Co (d) and (h).

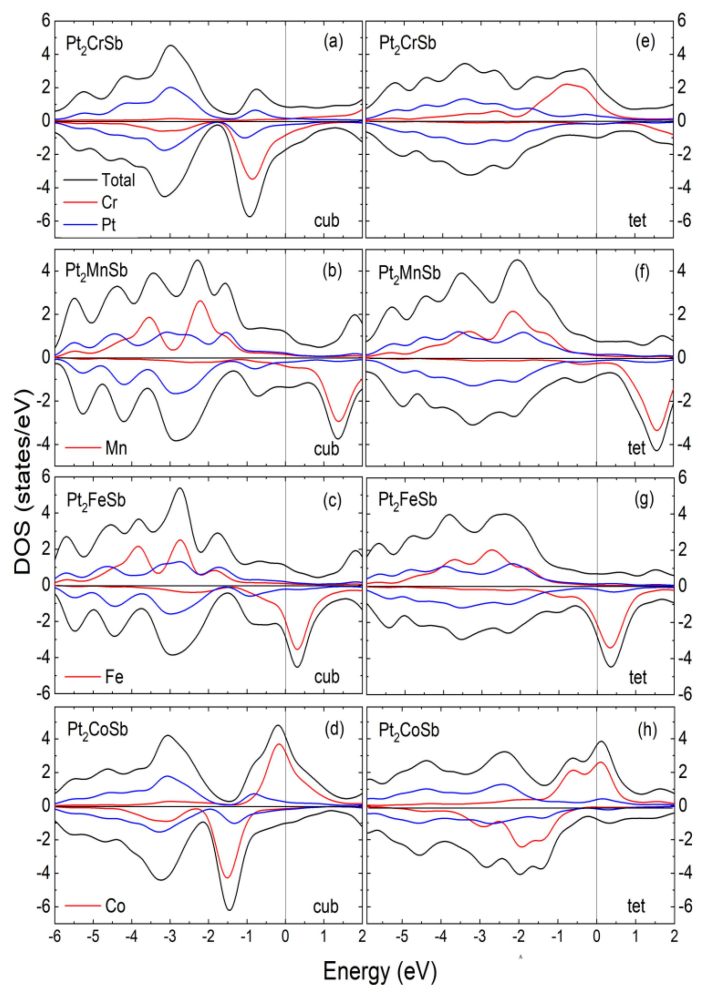

Fig. 5. Total and partial density of states of the cubic (left column) and tetragonal (right column) $\mathrm{Pt}_{2} \mathrm{YSb}$ alloys with $\mathrm{Y}=\mathrm{Cr}(\mathrm{a})$ and (e), Mn (b) and (f), Fe (c) and (g) and Co (d) and (h).

agree well with both the experimental and theoretical data [36, 37]. The mechanical criteria for the stable austenite phase are as follows: $C_{11}>0$, $C_{44}>0, C_{11}+2 C_{12}>0$ and $C_{11}-C_{12}>0$. From Table III, it is found that except for $\mathrm{Pt}_{2} \mathrm{CrAs}$, all the other Pt-based alloys do not satisfy the fourth stability condition. Thus, these alloys have negative values of the tetragonal shear modulus $C$, $C^{\prime}=0.5 \times\left(C_{11}-C_{12}\right)$. For $\mathrm{Pt}_{2} \mathrm{CrAs}$, the value of $C^{\prime}(2.75)$ is quite close to zero which is almost equal to that of $\mathrm{Ni}_{2} \mathrm{MnGa}$ (2.37). The softening of $C^{\prime}$ means that the alloys have a mechanically unstable austenite phase. Therefore, all the $\mathrm{Pt}_{2} \mathrm{YAs}$ and $\mathrm{Pt}_{2} \mathrm{YSb}$ alloys studied here are likely to undergo the austenite-martensite phase transition.

We now investigate the plastic property of the $\mathrm{Pt}_{2} \mathrm{YAs}$ and $\mathrm{Pt}_{2} \mathrm{YSb}$ alloys. According to the definition proposed by Pugh [38], we use the ratio of shear and bulk modulus $G / B$ to describe the plastic property of the alloys. A high value of the $G / B$ ratio is connected with the inherent brittleness, whereas a low value corresponds to the ductile nature. The critical value of $G / B$ separating brittleness and ductility is 0.57 . Following the earlier studies [16-18, 39], while calculating the $G / B$ ratio, the shear modulus $G_{\mathrm{V}}$ defined by Voigt [40] is considered as the value of $G$. In Table III, one can see that the $G_{\mathrm{V}} / B$ ratio of all the alloys is much smaller than the critical value of 0.57 and much lower than that of $\mathrm{Ni}_{2} \mathrm{MnGa}(0.43)$. 
TABLE III

Bulk mechanical properties of the cubic phase for the $\mathrm{Pt}_{2} \mathrm{YAs}$ and $\mathrm{Pt}_{2} \mathrm{YSb}$ alloys as well as the $\mathrm{Ni}_{2} \mathrm{MnGa}$ alloy.

\begin{tabular}{l|c|c|c|c|c|c|c|c}
\hline \hline Materials & $C_{11}[\mathrm{GPa}]$ & $C_{12}[\mathrm{GPa}]$ & $C_{44}[\mathrm{GPa}]$ & $C^{\prime}[\mathrm{GPa}]$ & $B[\mathrm{GPa}]$ & $G_{\mathrm{V}}[\mathrm{GPa}]$ & $G_{\mathrm{V}} / B$ & $C^{p}[\mathrm{GPa}]$ \\
\hline $\mathrm{Pt}_{2} \mathrm{CrAs}$ & 165.6 & 160.1 & 64.8 & 2.75 & 162. & 40. & 0.25 & 100.8 \\
$\mathrm{Pt}_{2} \mathrm{MnAs}$ & 151.6 & 171.1 & 51.7 & 9.8 & 164.6 & 27.1 & 0.16 & 99.9 \\
$\mathrm{Pt}_{2} \mathrm{FeAs}$ & 172.1 & 176.0 & 47.5 & 1.95 & 174.7 & 27.7 & 0.16 & 124.6 \\
$\mathrm{Pt}_{2} \mathrm{CoAs}$ & 144.6 & 180.6 & 56.7 & 18.0 & 168.6 & 26.8 & 0.16 & 87.9 \\
$\mathrm{Pt}_{2} \mathrm{CrSb}$ & 151.3 & 151.6 & 60. & 0.15 & 151.5 & 35.9 & 0.24 & 91.3 \\
$\mathrm{Pt}_{2} \mathrm{MnSb}$ & 138.9 & 153.3 & 50. & 7.2 & 148.8 & 27.1 & 0.18 & 88.9 \\
$\mathrm{Pt}_{2} \mathrm{FeSb}$ & 156.9 & 158.9 & 51.3 & 1.0 & 158.2 & 30.4 & 0.19 & 105.6 \\
$\mathrm{Pt}_{2} \mathrm{CoSb}$ & 138.1 & 163.7 & 57.9 & -12.8 & 155.2 & 29.6 & 0.19 & 80.2 \\
$\mathrm{Ni}_{2} \mathrm{MnGa}$ & 160.1 & 155.4 & 111.3 & 2.37 & 157.0 & 67.7 & 0.43 & 44.1 \\
& $152^{a}$ & $143^{a}$ & $103^{a}$ & $4.5^{a}$ & $146^{a}$ & $63.6^{a}$ & & \\
& $156^{b}$ & $143^{b}$ & $98^{b}$ & $6.5^{b}$ & & $61.4^{b}$ & & \\
\hline
\end{tabular}

${ }^{a}$ Ref. [37], ${ }^{b}$ Ref. [38].

On the other hand, a great value of the Cauchy pressure $C^{p}\left(C^{p}=C_{12}-C_{44}\right)$ of the alloy is indicative of the inherent ductility $[16,39]$. As presented in Table III, the $\mathrm{Pt}_{2} \mathrm{YAs}$ and $\mathrm{Pt}_{2} \mathrm{YSb}$ alloys have a greater value of the $C^{p}$ in comparison with $\mathrm{Ni}_{2} \mathrm{MnGa}$ (48.4 GPa). Therefore, it is concluded that the Pt-based alloys are new FSMAs with better ductility as compared to a typical $\mathrm{Ni}_{2}$-based alloy like $\mathrm{Ni}_{2} \mathrm{MnGa}$.

\section{Conclusions}

In this paper, the structural, magnetic, electronic and bulk mechanical properties of the $\mathrm{Pt}_{2} \mathrm{YAs}$ and $\mathrm{Pt}_{2} \mathrm{YSb}(\mathrm{Y}=\mathrm{Cr}, \mathrm{Mn}, \mathrm{Fe}$ and $\mathrm{Co}$ ) Heusler alloys have been investigated by using first-principles calculations. Our results indicate that all these alloys possess a regular structure in the austenite phases. The magnetic configurations for all the systems are ferromagnetic in nature. The instability of the austenite phases is demonstrated by analyzing the electronic density of states and the mechanical properties. The $\mathrm{Pt}_{2} \mathrm{YAs}$ and $\mathrm{Pt}_{2} \mathrm{YSb}$ alloys ( $\mathrm{Y}=\mathrm{Mn}, \mathrm{Fe}$, and $\mathrm{Co}$ ) are predicted to have much higher martensitic transition temperatures than that of $\mathrm{Ni}_{2} \mathrm{MnGa}$. Furthermore, the Pt-based alloys are more ductile alloys in comparison with $\mathrm{Ni}_{2} \mathrm{MnGa}$. Therefore, the $\mathrm{Pt}_{2} \mathrm{YAs}$ and $\mathrm{Pt}_{2} \mathrm{YSb}$ $(\mathrm{Y}=\mathrm{Mn}, \mathrm{Fe}$ and $\mathrm{Co})$ Heusler alloys emerge as promising potential candidates for FSMAs.

\section{Acknowledgments}

This work was supported by the Scientific Research Project of the Tianjin Education Committee (2019KJ130) and the National Natural Science Fund (11804384).

\section{References}

[1] K. Ullakko, J.K. Huang, C. Kantner, R.C. O'Handley, V.V. Kokorin, Appl. Phys. Lett. 69, 1966 (1996).
[2] S.J. Murray, M. Marioni, S.M. Allen, R.C. O'Handley, T.A. Lograsso, Appl. Phys. Lett. 77, 886 (2000).

[3] A. Sozinov, A.A. Likhachev, N. Lanska, K. Ullakko, Appl. Phys. Lett. 80, 1746 (2002).

[4] F.X. Hu, B. Shen, J. Sun, Appl. Phys. Lett. 76, 3460 (2000).

[5] F.X. Hu, J. Sun, G. Wu, B. Shen, J. Appl. Phys. 90, 5216 (2001).

[6] C. Biswas, R. Rawat, S.R. Barman, Appl. Phys. Lett. 86, 202508 (2005).

[7] A. Chakrabarti, M. Siewert, T. Roy, K. Mondal, A. Banerjee, M.E. Gruner, P. Entel, Phys. Rev. B 88, 174116 (2013).

[8] M. Kataoka, K. Endo, N. Kudo, T. Kanomata, H. Nishihara, T. Shishido, R.Y. Umetsu, M. Nagasako, R. Kainuma, Phys. Rev. B 82, 214423 (2010).

[9] S. Roy, E. Blackburn, S.M. Valvidares et al., Phys. Rev. B 79, 235127 (2009).

[10] A. Sozinov, N. Lanska, A. Soroka, W. Zou, Appl. Phys. Lett. 102, 021902 (2013).

[11] M. Siewert, M.E. Gruner, A. Dannenberg et al., Appl. Phys. Lett. 99, 191904 (2011).

[12] S. Singh, S.W. D'Souza, K. Mukherjee, P. Kushwaha, S.R. Barman, S. Agarwal, P.K. Mukhopadhyay, A. Chakrabarti, E.V. Sampathkumaran, Appl. Phys. Lett. 104, 231909 (2014).

[13] L. Caron, B. Dutta, P. Devi et al., Phys. Rev. B 96, 054105 (2017).

[14] S. Singh, S.W. D'Souza, J. Nayak, L. Caron, E. Suard, S. Chadov, C. Felser, Phys. Rev. B 93, 134102 (2016).

[15] B. Dutta, T. Hickel, P. Entel, J. Neugebauer, J. Phase Equilib. Diff. 35, 695 (2014). 
[16] T. Roy, M.E. Gruner, P. Entel, A. Chakrabarti, J. Alloys Compd. 632, 822 (2015).

[17] T. Roy, A. Chakrabarti, J. Magn. Magn. Mater. 401, 929 (2016).

[18] X. Yang, Y. Wang, M.R. Du, Y.X. Xue, J. Appl. Phys. 126, 085103 (2019).

[19] P. Hohenberg, W. Kohn, Phys. Rev. 136, B864 (1964).

[20] W. Kohn, L.J. Sham, Phys. Rev. 140, A1133 (1965).

[21] X. Tang, W.G. Sun, Y.T. Gu, C. Lu, L.Z. Kou, C.F. Chen, Phys. Rev. B 99, 045445 (2019).

[22] C. Lu, C.F. Chen, J. Phys. Chem. Lett. 9, 2181 (2018).

[23] C. Lu, M. Amsler, C.F. Chen, Phys. Rev. B 98, 054102 (2018).

[24] S. Aron-Dine, G.S. Pomrehn, A. PribramJones, K.J. Laws, L. Bassman, Phys. Rev. B 95, 024108 (2017).

[25] C. Lu, Q. Li, Y.M. Ma, C.F. Chen, Phys, Rev. Lett. 119, 115503 (2017).

[26] A. Talapatra, R. Arróyave, P. Entel, I. Valencia-Jaime, A.H. Romero, Phys. Rev. B 92, 054107 (2015).

[27] L. Wollmann, S. Chadov, J. Kübler, C. Felser,Phys. Rev. B 92, 064417 (2015).
[28] L. Wollmann, S. Chadov, J. Kübler, C. Felser, Phys. Rev. B 90, 214420 (2014).

[29] C. Lu, M.S. Miao, Y.M. Ma, J. Am. Chem. Soc. 135, 14167 (2013).

[30] J.P. Perdew, K. Burke, M. Ernzerhof, Phys. Rev. Lett. 77, 3865 (1996).

[31] L. Feng, W.X. Wang, E.K. Liu, W.H. Wang, G.H. Wu, Funct. Mater. Lett. 8, 1550064 (2015).

[32] Y.W. Ma, S. Awaji, K. Watanabe, M. Matsumoto, N. Kobayashi, Solid State Commun. 113, 671 (2000).

[33] S.R. Barman, A. Chakrabarti, S. Singh et al., Phys. Rev. B 78, 134406 (2008).

[34] A.T. Zayak, P. Entel, K.M. Rabe, W.A. Adeagbo, M. Acet,Phys. Rev. B 72, 054113 (2005).

[35] C.-M. Li, H.-B. Luo, Q.-M. Hu, R. Yang, B. Johansson, L. Vitos, Phys. Rev. B 82, 024201 (2010).

[36] J. Worgull, E. Petti, J. Trivisonno, Phys. Rev. B 54, 15695 (1996).

[37] T.E. Stenger, J. Trivisonno, Phys. Rev. B 57, 2735 (1998).

[38] S.F. Pugh, Philos. Mag. 45, 823 (1954).

[39] T. Roy, D. Pandey, A. Chakrabarti, Phys. Rev. B 93, 184102 (2016).

[40] W. Voigt, Ann. Phys. 274, 573 (1889). 